University of Wollongong

Research Online

Australian Institute for Innovative Materials -

Papers

Australian Institute for Innovative Materials

$1-1-2019$

Electrochemical potassium/lithium-ion intercalation into TiSe2: Kinetics and mechanism

Peng Li

University of Wollongong, pl465@uowmail.edu.au

Xiaobo Zheng

University of Wollongong, xz963@uowmail.edu.au

Haoxiang Yu

Ningbo University

Guoqiang Zhao

University of Wollongong, gz815@uowmail.edu.au

Jie Shu

Ningbo University

See next page for additional authors

Follow this and additional works at: https://ro.uow.edu.au/aiimpapers

Part of the Engineering Commons, and the Physical Sciences and Mathematics Commons

Research Online is the open access institutional repository for the University of Wollongong. For further information contact the UOW Library: research-pubs@uow.edu.au 


\title{
Electrochemical potassium/lithium-ion intercalation into TiSe2: Kinetics and mechanism
}

\author{
Abstract \\ As one promising candidate for next-generation energy storage systems, K-ion batteries (KIBs) attract \\ increasing research attention due to the element abundance, low cost, and competent energy density as \\ compared to Li-ion batteries. However, developing practical electrode materials in particular cathodes for \\ KIBs is still in its infancy, and the related reaction mechanisms of the electrode materials are far from \\ completely understood. In this work, TiSe2was, for the first time, investigated as an intercalated-type \\ electrode for potassium storage due to its large interlayer space. The potassiation/depotassiation \\ reaction mechanism was unraveled based on the analysis of in-situ X-ray diffraction (XRD), ex-situ X-ray \\ photoelectron spectroscopy (XPS), and ex-situ transmission electron microscope (TEM) results. \\ Meanwhile, the lithium storage behaviour and the relevant lithiation/delithiation reaction mechanism were \\ also studied in detail. The results reveal that $\mathrm{K}+$ show lower diffusion coefficient and hence more sluggish \\ intercalation reaction kinetics as compared with $\mathrm{Li}+$. In addition, the intercalation reaction of $\mathrm{K}+$ would \\ cause irreversible structure changes, while the intercalation reaction is fully reversible for Li+counterpart.

\section{Disciplines} \\ Engineering | Physical Sciences and Mathematics

\section{Publication Details} \\ Li, P., Zheng, X., Yu, H., Zhao, G., Shu, J., Xu, X., Sun, W. \& Dou, S. Xue. (2019). Electrochemical potassium/ \\ lithium-ion intercalation into TiSe2: Kinetics and mechanism. Energy Storage Materials, 16 512-518.

\section{Authors} \\ Peng Li, Xiaobo Zheng, Haoxiang Yu, Guoqiang Zhao, Jie Shu, Xun Xu, Wenping Sun, and Shi Xue Dou
}




\section{Electrochemical Potassium/Lithium-ion Intercalation into TiSe $e_{2}$ : Kinetics and}

\section{Mechanism}

Peng $\mathrm{Li}^{\mathrm{a}}$, Xiaobo Zheng ${ }^{\mathrm{a}}$, Haoxiang $\mathrm{Yu}^{\mathrm{b}}$, Guoqiang Zhao ${ }^{\mathrm{a}}$, Jie Shu ${ }^{\mathrm{b}, *}$, Xun $\mathrm{Xu}^{\mathrm{a}}$, Wenping Sun $^{\mathrm{a}, *}$, Shi Xue Dou ${ }^{\mathrm{a}}$

${ }^{a}$ Institute for Superconducting \& Electronic Materials, Australian Institute for Innovative Materials, University of Wollongong, Wollongong, NSW 2522, Australia

${ }^{\mathrm{b}}$ Faculty of Materials Science and Chemical Engineering, Ningbo University, Ningbo 315211 , Zhejiang (P. R. China)

*Corresponding Authors: sergio_shu@hotmail.com (J. Shu), wenping@uow.edu.au (W. Sun)

Abstract: As one promising candidate for next-generation energy storage systems, K-ion batteries (KIBs) attract increasing research attention due to the element abundance, low cost, and competent energy density as compared to Li-ion batteries. However, developing practical electrode materials in particular cathodes for KIBs is still in its infancy, and the related reaction mechanisms of the electrode materials are far from completely understood. In this work, $\mathrm{TiSe}_{2}$ was, for the first time, investigated as an intercalated-type electrode for potassium storage due to its large interlayer space. The potassiation/depotassiation reaction mechanism was unraveled based on the analysis of in-situ X-ray diffraction (XRD), ex-situ Xray photoelectron spectroscopy (XPS), and ex-situ transmission electron microscope (TEM) results. Meanwhile, the lithium storage behaviour and the relevant lithiation/delithiation reaction mechanism were also studied in detail. The results reveal that $\mathrm{K}^{+}$show lower diffusion coefficient and hence more sluggish intercalation reaction kinetics as compared with $\mathrm{Li}^{+}$. In addition, the intercalation reaction of $\mathrm{K}^{+}$would cause irreversible structure changes, while the intercalation reaction is fully reversible for $\mathrm{Li}^{+}$counterpart.

Keywords: $\mathrm{TiSe}_{2}$, K-ion batteries, Li-ion batteries, reaction mechanism, diffusion kinetics

\section{Introduction}

Currently, Li-ion batteries (LIBs) dominate the market of portable electronic devices and are extending their applications in electric vehicles and renewable energy storage due to their 
high energy density and power density. [1, 2] However, the scarcity of lithium resources in Earth's crust and the high extraction cost will inevitably restrict its long-term applications. [3, 4] Hence, increasing attention has been transferred to Na-ion batteries due to the costeffective, natural abundance of sodium resources, and chemical similarity with Li-ion batteries.[5, 6] Unfortunately, Na-ion batteries possess relative low energy density because the standard electrode potential of $\mathrm{Na}^{+} / \mathrm{Na}(-2.714 \mathrm{~V}$ vs. SHE) is $300 \mathrm{mV}$ higher than that of $\mathrm{Li}^{+} / \mathrm{Li}(-3.040 \mathrm{~V}$ vs. SHE), which limits their potential industrial applications. [6, 7] Recently, potassium-ion batteries (KIBs) has emerged as one promising alternative to LIBs based on their unique properties.[8] Firstly, the standard electrode potential of $\mathrm{K}^{+} / \mathrm{K}(-2.936 \mathrm{~V}$ vs. SHE) is $220 \mathrm{mV}$ lower than $\mathrm{Na}$ counterpart, which contributes to wider electrochemical voltage window and improved energy density for KIBs. [4, 9] In electrolyte system, the standard potential of $\mathrm{K}^{+} / \mathrm{K}$ could exhibit more negative than that of $\mathrm{Li}^{+} / \mathrm{Li}$. Here is an example that $\mathrm{K}^{+} / \mathrm{K}$ potential is $-0.15 \mathrm{~V}$ vs $\mathrm{Li}^{+} / \mathrm{Li}$ reference in ethylene carbonate/diethyl carbonate (EC/DEC) electrolyte, indicating its advantage in non-aqueous medium compared to LIBs. [4, 8] Secondly, potassium resources (2.09 wt \%) are also much abundant than lithium $(0.0017$ wt $\%)$ in the crust of Earth and can be extracted with a much reduced cost. [9, 10] In addition, the current collector $(\mathrm{Cu})$ in LIBs can be replaced by aluminum as no formation of $\mathrm{K}-\mathrm{Al}$ alloys at low potential, thus decreasing the production cost of battery. All of these intrinsic advantages of KIBs enable them to be promising candidates in energy storage field; however, the exploration of KIBs electrode materials is full of challenge due to the larger radius size of $\mathrm{K}^{+}(1.38 \AA)$ and its highly reactivity.[7]

Recently, the research attention on KIBs' electrode materials is mainly focused on carbonaceous materials, alloying-type materials, transition metal oxides and dichalcogenides (TMDs) $\left(\mathrm{TiS}_{2}\right.$ or $\left.\mathrm{MoS}_{2}\right)$. [11-17] However, it has to be noted that the electrochemical performances for potassium storage of the aforementioned materials are much inferior to their corresponding lithium counterparts. Specifically, the in-depth understanding the related 
reaction mechanisms for potassium storage still remains a great challenge. Among various 2D TMDs, $\mathrm{TiSe}_{2}$ has been widely investigated on its charge density wave (CDW) instability owning to its quasi-two-dimensional electronic structures. [18] In the meantime, its application potential in rechargeable batteries gains much emphasis considering $\mathrm{TiSe}_{2}$ features large interlayer space and much higher electrical conductivity. [19] The electrochemical behavious of $\mathrm{TiSe}_{2}$ in $\mathrm{Mg}$-ion battery and Na-ion battery have been investigated, and both cases could exhibit promising reversibility and decent cycling performances. [20,21] To date, there has been no report regarding the electrochemical behavious of $\mathrm{TiSe}_{2}$ for potassium and lithium storage. Considering the larger interlayer space, it can be speculated that $\mathrm{TiSe}_{2}$ might be a promising alternative electrode material for KIBs. In this work, we, for the first time, systematically investigated the potassium/lithium storage behaviours of $\mathrm{TiSe}_{2}$ with specific emphasis on intercalation reaction kinetics and the related mechanisms. The intercalation reaction kinetics was studied by means of GITT analysis and the intercalation reaction mechanisms of $\mathrm{TiSe}_{2}$ were uncovered based on in-situ XRD, ex-situ TEM, and ex-situ XPS characterizations.

\section{Experimental Section}

\subsection{Material synthesis and characterization}

$\mathrm{TiSe}_{2}$ was synthesized by a powder sintering method at high temperature $\left(650{ }^{\circ} \mathrm{C}\right)$. Typically, stoichiometric amount $\mathrm{Ti}$ and Se powder was mixed uniformly and sealed in an evacuated quartz tube. Subsequently, the quartz tube was placed in Muffle furnace and calcined at $650{ }^{\circ} \mathrm{C}$ for $8 \mathrm{~h}\left(5^{\circ} \mathrm{C} \min ^{-1}\right)$ to obtain the target product. X-ray diffraction (XRD) data was collected by a GBCMMA diffractometer with $\mathrm{Cu} \mathrm{K} \alpha$ radiation at a scanning rate of $1^{\mathrm{o}} \mathrm{min}^{-1}$. The X-ray photoelectron spectroscopy (XPS) spectrum was tested on a Phoibos Xray photoelectron spectrometer (100 Analyser, SPECS, Germany, AlKa X-rays). The morphologies of $\mathrm{TiSe}_{2}$ were captured by field-emission scanning electron microscopy 
(FESEM) (JEOL 7500) and transmission electron microscope (TEM) (JEOL 2010). Raman measurement was performed with a Raman JY HR800 Spectrometer.

\subsection{Electrochemical measurements}

Electrochemical performance was obtained by testing CR 2032 coin cells, which were assembled in an argon-filled glove box. The working electrodes were fabricated by mixing 70 wt.\% active materials (as-prepared $\mathrm{TiSe}_{2}$ ), 20 wt.\% Super $\mathrm{P}$ and 10 wt.\% poly(vinyl difluoride) (PVDF) in Nmethyl-2-pyrrolidone (NMP) solvent. Then the slurry was uniformly coated onto $\mathrm{Al}$ foil, vacuum dried at $80{ }^{\circ} \mathrm{C}$ for overnight, pressed at $200 \mathrm{Kg} \mathrm{cm}^{-2}$, and punched into discs. In terms of batteries assembling, Li foil was used as the counter electrode in LIBs, $\mathrm{K}$ metal was used as the counter electrode in KIBs, and glass fibre paper was used as the separators. For K-ion batteries testing, the electrolyte was $0.8 \mathrm{M} \mathrm{KPF}_{6}$ dissolved in EC/DEC (1:1 in volume). In terms of Li-ion batteries testing, the electrolyte was $1 \mathrm{M} \mathrm{LiPF}_{6}$ solution in a mixture of ethylene carbonate (EC), dimethyl carbonate (DMC) and diethyl carbonate (DEC) (1:1:1 in volume). Cyclic voltammetry (CV) was performed by a Biologic VMP-3 electrochemical work station over the potential range of 1.0-3.0 V and 1.5-3.0 V for $\mathrm{K}$ - and Li-ion batteries, respectively, at a scanning rate of $0.1 \mathrm{mV} \mathrm{s}^{-1}$. Galvanostatic discharge/charge measurements and Galvanostatic Intermittent Titration Technique (GITT) tests were carried out using a LAND Battery Tester at a voltage window of 1.0-3.0 V and 1.53.0 $\mathrm{V}$ for $\mathrm{K}$ - and Li-ion batteries, respectively. In the measurement, the cell was repeatedly discharged/charged at $20 \mathrm{~mA} \mathrm{~g}^{-1}(\sim 0.15 \mathrm{C})$ for $10 \mathrm{~min}(\tau)$, followed by a potential relaxation step for $50 \mathrm{~min}$ at open circuit. Thus the cell was in a steady-state and the voltage was maintained at a stable value (Es). All electrochemical studies were carried out at room temperature. 
The in-situ XRD data was collected with Bruker D8 Focus X-ray diffraction instrument. In terms of in-situ XRD observation, $\mathrm{TiSe}_{2}$ was mixed with carbon black with a mass ratio of 4:1, and then ground uniformly by hand in agate mortar to form the powder electrode. In a live and specially designed in-situ cell, metallic Be disc was used as X-ray transmission window thus the powder electrode, separator, metal discs as well as electrolyte were added in sequence to assemble the battery. The detailed structure of in-situ battery was described in related paper. [22] In terms of in-situ batteries testing, the $\mathrm{TiSe}_{2}$ powder electrode was coupled with potassium/lithium discs and operated at a small current density within a voltage window of 1.0-3.0 $\mathrm{V}$ and 1.5-3.0 V, respectively. The obtained in-situ XRD patterns and voltage profiles are discussed in the following section.

\section{Results and Discussion}

The morphology of the as-prepared $\mathrm{TiSe}_{2}$ and its phase characterizations are illustrated in Figure 1. According to the Rietveld refined XRD pattern of $\mathrm{TiSe}_{2}$ as shown in Figure 1a, the observed Bragg positions are indexed to a hexagonal lattice with $P-3 m 1$ (No. 164) space group and lattice parameters of $\mathbf{a}=\mathbf{b}=3.54048 \AA$ and $\mathbf{c}=6.00793 \AA$ (Table S1, Supporting Information). Through the [110] direction, the crystal structure of $\mathrm{TiSe}_{2}$, together with the octahedral and tetrahedral sites is presented in Figure 1b. The Ti atom bonds with its adjacent six Se atoms, which forms Ti-Se octahedron unit cell and constitutes the basic framework of $\mathrm{TiSe}_{2}$. The interlayer space $(0.601 \mathrm{~nm})$ between two layers provides ideal accommodation sites for alkaline metal ions and the intercalation sites are displayed according to previous reports.[23-25] Therefore, the $\mathrm{K}^{+}$or $\mathrm{Li}^{+}$are intercalated/deintercalated into the specified sites thus offer reversible capacities during the discharge/charge processes. The detailed intercalation mechanisms of $\mathrm{K}^{+} / \mathrm{Li}^{+}$are discussed in the following sections. From the SEM image in Figure S1 (Supporting Information), the $\mathrm{TiSe}_{2}$ exhibits stacked layers and typical plate-like structure. In addition, Figure 1c gives the TEM morphology of nanosheet $\mathrm{TiSe}_{2}$ and its crystal lattice fringes in HRTEM (Figure 1d) reveal the lattice spacing of $0.27 \mathrm{~nm}$, which 
is in good agreement with the (101) plane of $\mathrm{TiSe}_{2}$. Moreover, two vibration peaks of Raman spectra (Figure 1e), which centered at around 199.5 and $134.7 \mathrm{~cm}^{-1}$ respectively, correspond to $\mathrm{A}_{1 \mathrm{~g}}$ and $\mathrm{E}_{\mathrm{g}}$ symmetries of $\mathrm{TiSe}_{2}$. [26]

The electrochemical properties of $\mathrm{TiSe}_{2} / \mathrm{K}$ and $\mathrm{TiSe}_{2} / \mathrm{Li}$ cells were first investigated at a current density of $65 \mathrm{~mA} \mathrm{~g}^{-1}(0.5 \mathrm{C})$. As described in Figure 2a, for potassium storage, the discharge/charge curves have four voltage plateaus at around 2.05/2.31, 1.76/2.17, 1.27/1.88, and $1.19 / 1.43 \mathrm{~V}$, respectively. And the cell delivers the initial charge capacity of $92.7 \mathrm{~mA} \mathrm{~h} \mathrm{~g}^{-}$ ${ }^{1}$, indicative of the uptake of $\sim 0.71 \mathrm{~K}^{+}$every $\mathrm{TiSe}_{2}$ formula (Figure 2a and Figure S2a, Supporting Information), as well as maintains the reversible capacity to be $64.7 \mathrm{~mA} \mathrm{~h} \mathrm{~g}$ during the $100^{\text {th }}$ cycle. Figure $2 \mathrm{~b}$ shows the $\mathrm{CV}$ curves of $\mathrm{TiSe}_{2} / \mathrm{K}$ within the potential range of 1.0-3.0 $\mathrm{V}$ at a scan rate of $0.1 \mathrm{mV} \mathrm{s}^{-1}$. There are four reversible redox couples located at $1.97 / 2.32,1.75 / 2.16,1.27 / 1.86$, and $1.17 / 1.43 \mathrm{~V}$, which is consistent with the profiles of the discharge/charge curves. While in Figure 2c, the first charge capacity of $\mathrm{TiSe}_{2} / \mathrm{Li}$ reaches 121.6 $\mathrm{mA} \mathrm{h} \mathrm{g}^{-1}$, corresponding to the deintercalation of $\sim 0.93 \mathrm{Li}^{+}$per $\mathrm{TiSe}_{2}$ structure unit, and the reversible capacity decreases to $109.7 \mathrm{~mA} \mathrm{~h} \mathrm{~g}^{-1}$ during the $100^{\text {th }}$ cycle (Figure $\mathrm{S} 2 \mathrm{~b}$, Supporting Information). As can be seen from the first three CV curves of $\mathrm{TiSe}_{2} / \mathrm{Li}$ (Figure $2 \mathrm{~d})$, three redox peaks at around 1.92/2.20, 1.71/2.05, and 1.63/1.83 $\mathrm{V}$ are in good agreement with the discharge/charge curves. The rate capabilities and long cycling performances of $\mathrm{TiSe}_{2} / \mathrm{K}$ and $\mathrm{TiSe}_{2} / \mathrm{Li}$ are shown in Figure $2 \mathrm{e}-2 \mathrm{~g}$. The average charge capacities of $\mathrm{TiSe}_{2} / \mathrm{K}$ are $89.0,75.0,66.6,58.1,52.3,47.9$, and $44.5 \mathrm{~mA} \mathrm{~h} \mathrm{~g}^{-1}$ at the current densities of 50, 100, $200,400,600,800$, and $1000 \mathrm{~mA} \mathrm{~g}^{-1}$, respectively. When the current density recovers to 50 $\mathrm{mA} \mathrm{g}^{-1}$, the charge capacity increases to $78.5 \mathrm{~mA} \mathrm{~h} \mathrm{~g}^{-1}$. By contrast, TiSe 2 exhibits better rate capability for lithium storage, and the charge capacity still has a high capacity retention of $90.8 \mathrm{~mA} \mathrm{~h} \mathrm{~g}^{-1}$ at $1000 \mathrm{~mA} \mathrm{~g}^{-1}$. The charge capacity recovers to $117.3 \mathrm{~mA} \mathrm{~h} \mathrm{~g}^{-1}$ after switching the current density to $50 \mathrm{~mA} \mathrm{~g}^{-1}$. It is worth mentioning that the capacity of $\mathrm{TiSe}_{2} / \mathrm{K}_{\text {degrades }}$ more quickly as compared to $\mathrm{TiSe}_{2} / \mathrm{Li}$. $\mathrm{TiSe}_{2} / \mathrm{K}$ and $\mathrm{TiSe}_{2} / \mathrm{Li}$ maintain capacity retention of 
$61.1 \%$ and $80.7 \%$, respectively, after 300 cycles even at a current density of $400 \mathrm{~mA} \mathrm{~g}^{-1}$. Particularly, the $\mathrm{K}^{+} / \mathrm{Li}^{+}$intercalation capacity of $\mathrm{TiSe}_{2}$ is close to that of $\mathrm{TiS}_{2}$ though the theoretical capacity of $\operatorname{TiSe}_{2}\left(130.2 \mathrm{~mA} \mathrm{~h} \mathrm{~g}^{-1}\right)$ is much lower than $\mathrm{TiS}_{2}\left(240.0 \mathrm{~mA} \mathrm{~h} \mathrm{~g}{ }^{-1}\right)$. [15, 16] The result suggests that faster intercalation reaction kinetics is achieved in $\mathrm{TiSe}_{2}$ as compared to $\mathrm{TiS}_{2}$.

In order to gain a better understanding of the reaction kinetics of $\mathrm{TiSe}_{2} / \mathrm{K}$ and $\mathrm{TiSe}_{2} / \mathrm{Li}$, GITT is used to evaluate the chemical diffusion coefficients of $\mathrm{K}^{+}$and $\mathrm{Li}^{+}$. Figure 3a presents the GITT profiles of $\mathrm{TiSe}_{2} / \mathrm{K}$ during the $1^{\text {st }}$ cycle. One typical single step of titration at around $1.73 \mathrm{~V}$ is presented in Figure $3 \mathrm{~b}$ with related parameters schematically labelled. The $\mathrm{D}_{\mathrm{K}+}$ can be determined by applying Fick's second law of diffusion and was calculated by Eq. (1) [27, 28]:

$D_{K^{+}}=\frac{4}{\pi}\left(\frac{m_{B} V_{M}}{M_{B} A}\right)^{2}\left(\frac{\Delta E_{s}}{\tau\left(d E_{\tau} / \mathrm{d} \sqrt{\tau}\right)}\right)^{2}\left(\tau<<L^{2} / D_{K^{+}}\right)$

Here, the $m_{B}, V_{M}$, and $M_{B}$ are the mass, the molar volume, and the molecular weight of the electrode material. A is the surface area of the electrode, and $\mathrm{L}$ is the diffusion length. In view of the linear relationship between cell voltage and $\tau^{1 / 2}$ (Figure S3, Supporting Information), thus the Eq. (1) can be further simplified as Eq. (2):

$$
D_{K^{+}}=\frac{4}{\pi \tau}\left(\frac{m_{B} V_{M}}{M_{B} A}\right)^{2}\left(\frac{\Delta E_{s}}{\Delta E_{\tau}}\right)^{2}
$$

Based on the calculated results, the profiles of $\log \left(D_{K^{+}}\right)$vs. voltage are displayed in Figure $3 \mathrm{c}$ and the $\mathrm{D}_{\mathrm{K}+}$ values are ranging from $3.37 \times 10^{-12}$ to $1.99 \times 10^{-9} \mathrm{~cm}^{2} \mathrm{~s}^{-1}$ during the whole discharge/charge processes. The GITT profile of $\mathrm{TiSe}_{2} / \mathrm{Li}$ during the $1^{\text {st }}$ cycle together with its one single titration step at around $1.93 \mathrm{~V}$ is illustrated in Figure 3d-3e. The chemical coefficients of lithium $\left(\mathrm{D}_{\mathrm{Li}+}\right)$ are between $2.54 \times 10^{-11}$ to $6.73 \times 10^{-10} \mathrm{~cm}^{2} \mathrm{~s}^{-1}$ in the whole voltage window (Figure 3f). The characteristics of the chemical coefficients can be classified 
into two regions: ions intercalation/deintercalation processes and nonintercalation/deintercalation stages, which can be also observed in many typical intercalationtype electrode materials. [28-30] Initially (from open circuit voltage to where the first voltage plateau appears), the values of $\mathrm{D}_{\mathrm{k}+}$ are in the range of $3.58 \times 10^{-11}$ to $8.92 \times 10^{-11} \mathrm{~cm}^{2} \mathrm{~s}^{-1}$, which is around one order of magnitude lower than that of $\mathrm{D}_{\mathrm{Li}^{+}}$(between $2.73 \times 10^{-10}$ and $4.67 \times 10^{-10}$ $\mathrm{cm}^{2} \mathrm{~s}^{-1}$ ) in $\mathrm{TiSe}_{2} / \mathrm{Li}$ system. As the intercalation reaction happens, both the diffusion coefficients of $\mathrm{K}^{+}$and $\mathrm{Li}^{+}$decrease with the formation of new phases. Specifically, the values of $\mathrm{D}_{\mathrm{k}+}$ at the first $\mathrm{K}^{+}$-intercalation stage vary from $6.54 \times 10^{-12}$ to $3.37 \times 10^{-12} \mathrm{~cm}^{2} \mathrm{~s}^{-1}$, accompanied with the phase change from $\mathrm{TiSe}_{2}$ to $\mathrm{K}_{0.25} \mathrm{TiSe}_{2}$. At the same time, the diffusion coefficients of $\mathrm{Li}^{+}$range from $3.53 \times 10^{-10}$ to $1.13 \times 10^{-10} \mathrm{~cm}^{2} \mathrm{~s}^{-1}$ when the phase evolutes from $\mathrm{TiSe}_{2}$ to $\mathrm{Li}_{0.33} \mathrm{TiSe}_{2}$, which is around two orders of magnitude higher than that of $\mathrm{K}^{+}$. In the next stage, the phase $\mathrm{K}_{0.25} \mathrm{TiSe}_{2}$ continually transforms into $\mathrm{K}_{0.58} \mathrm{TiSe}_{2}$ with further $\mathrm{K}^{+}$ intercalation, and the diffusion coefficients of $\mathrm{K}^{+}$in this phase transformation region are in the range of $8.94 \times 10^{-10}-5.92 \times 10^{-10} \mathrm{~cm}^{2} \mathrm{~s}^{-1}$. Interestingly, the values of $\mathrm{D}_{\mathrm{Li}+}$ in this phase transformation stage are in the range of $3.50 \times 10^{-10}-4.28 \times 10^{-10} \mathrm{~cm}^{2} \mathrm{~s}^{-1}$, which is slightly lower than $\mathrm{D}_{\mathrm{k}+}$. This might correlate with the structural difference between $\mathrm{K}_{0.25} \mathrm{TiSe}_{2}$ and $\mathrm{Li}_{0.33} \mathrm{TiSe}_{2}$ during further intercalation. The much larger layer distance of $\mathrm{K}_{0.25} \mathrm{TiSe}_{2}$ $(\mathrm{c}=42.355 \AA)$ might make it a bit easier for $\mathrm{K}^{+}$intercalation than $\mathrm{Li}^{+}$from $\mathrm{Li}_{0.33} \mathrm{TiSe}_{2}$ $(c=25.983 \AA)$ to $\mathrm{LiTiSe}_{2}$. The schematic illustrations of the crystal structures of these intermediate phases are presented in Figure S8-S9 (Supporting Information). Finally, the diffusion coefficients of $\mathrm{K}^{+}$decrease to $5.00 \times 10^{-11}-1.79 \times 10^{-11} \mathrm{~cm}^{2} \mathrm{~s}^{-1}$ along with the phase transformation from $\mathrm{K}_{0.58} \mathrm{TiSe}_{2}$ to $\mathrm{K}_{x} \mathrm{TiSe}_{2}$. In addition, the values of $\mathrm{D}_{\mathrm{Li}+}$ change slightly $\left(3.91 \times 10^{-10}-9.10 \times 10^{-11} \mathrm{~cm}^{2} \mathrm{~s}^{-1}\right)$ with the formation of $\mathrm{LiTiSe}_{2}$, which is approximately one order of magnitude higher than that of $\mathrm{D}_{\mathrm{k}+}$. While in the reverse charge process, nearly identical evolution of diffusion coefficients of $\mathrm{K}^{+}$and $\mathrm{Li}^{+}$can be observed as compared to discharge process. The value of $\mathrm{D}_{\mathrm{k}^{+}}$is determined to be $4.16 \times 10^{-10}, 1.54 \times 10^{-10}$, and $8.94 \times 10^{-12}$ 
$\mathrm{cm}^{2} \mathrm{~s}^{-1}$ along with the phase change from $\mathrm{K}_{x} \mathrm{TiSe}_{2}$ to $\mathrm{K}_{0.58} \mathrm{TiSe}_{2}, \mathrm{~K}_{0.58} \mathrm{TiSe}_{2}$ to $\mathrm{K}_{0.25} \mathrm{TiSe}_{2}$, and $\mathrm{K}_{0.25} \mathrm{TiSe}_{2}$ to $\mathrm{TiSe}_{2}$, respectively. Meanwhile, $\mathrm{D}_{\mathrm{Li}+}$ is $5.47 \times 10^{-10}$ and $2.54 \times 10^{-11}$ accompanied with the phase evolution from $\mathrm{LiTiSe} e_{2}$ to $\mathrm{Li}_{0.33} \mathrm{TiSe}_{2}$, and $\mathrm{Li}_{0.33} \mathrm{TiSe}_{2}$ to $\mathrm{TiSe}_{2}$, which is one order of magnitude higher than that of $\mathrm{D}_{\mathrm{k}+}$. On the basis of the aforementioned discussion, it can be concluded that $\mathrm{Li}^{+}$exhibit faster diffusion kinetics in $\mathrm{TiSe}_{2} / \mathrm{Li}$ system than $\mathrm{K}^{+}$in $\mathrm{TiSe}_{2} / \mathrm{K}$ system, which is the intrinsic reason for the better rate capability of $\mathrm{TiSe}_{2} / \mathrm{Li}$ as depicted in the Figure 2e and 2f.

The intercalation reaction mechanisms of $\mathrm{TiSe}_{2} / \mathrm{K}$ and $\mathrm{TiSe}_{2} / \mathrm{Li}$ were systematically investigated by means of in-situ XRD, ex-situ TEM, and ex-situ XPS. Figure 4a shows the insitu XRD patterns of $\mathrm{TiSe}_{2} / \mathrm{K}$ during the first two cycles, and the voltage profiles are presented in Figure 4d. Worth noting, the peaks at $38.7^{\circ}$ and $41.4^{\circ}$ are ascribed to $\mathrm{BeO}$, which are arising from the X-ray transmission window $(\mathrm{Be})$. At the beginning, the $\mathrm{TiSe}_{2} / \mathrm{K}$ cell presents an initial open circuit voltage of $2.90 \mathrm{~V}$ and the diffraction peaks displayed in Figure 4a-4c and Figure S4a (Supporting Information) are originating from the pristine $\mathrm{TiSe}_{2}$ phase. In the first stage $(0<x<0.25)$, the relative intensity of (001), (002), (101), and (102) diffraction peaks becomes gradually weakened with Bragg positions unchanged. Upon further intercalation, three newly formed peaks can be indexed to (006), (106), and (108) planes of $\mathrm{K}_{0.25} \mathrm{TiSe}_{2}$ (PDF No. 32-0862) (Figure S4b, Supporting Information), as indicated by the black dash circles in Figure 4a-4b. Subsequently, the biphase ( $\mathrm{TiSe}_{2}$ and $\mathrm{K}_{0.25} \mathrm{TiSe}_{2}$ ) undergoes a gradual transformation to triphase accompanied with the formation of $\mathrm{K}_{0.58} \mathrm{TiSe}_{2}$ (PDF No. 32-0863) (Figure S4c, Supporting Information). As the voltage falls to $1.0 \mathrm{~V}$, the intercalation reaction ends with one newly formed phase, $\mathrm{K}_{x} \mathrm{TiSe}_{2}(0.58<x<1)$, with two characteristic diffraction peaks marked by pink dash circles. During the charge process, the $\mathrm{K}_{x} \mathrm{TiSe}_{2}(0.58<x<1)$ phase transforms into $\mathrm{K}_{0.58} \mathrm{TiSe}_{2}, \mathrm{~K}_{0.25} \mathrm{TiSe}_{2}$, and $\mathrm{TiSe}_{2}$ in sequence along with $\mathrm{K}^{+}$deintercalation. The existence of an unknown phase $\mathrm{K}_{y} \mathrm{TiSe}_{2}$ in the fully charged state implies the partially irreversible structural evolution. A slighly different phase transformation 
behaviour was reported in the $\mathrm{TiS}_{2} / \mathrm{K}$ system.[15, 16] As illustrated by Tian et al., the discharged phase $\mathrm{K}_{0.88} \mathrm{TiS}_{2}$ cannot recover back to $\mathrm{TiS}_{2}$ during the initial cycle due to the structural distortion induced by $\mathrm{K}^{+}$intercalation.[15] Li et al., suggested that $\mathrm{K}^{+}$intercalation favours a Daumas-Hérold model accompanied by the partially irreversible phase change from $\mathrm{TiS}_{2}$ to $\mathrm{K}_{0.56} \mathrm{TiS}_{2}$.[16] In contrast, for $\mathrm{Li}^{+}$intercalation/deintercalation, $\mathrm{TiSe}_{2}$ presents continuous and periodical phase evolution from $\mathrm{TiSe}_{2}$ to $\mathrm{Li}_{0.33} \mathrm{TiSe}_{2}$ and then to $\mathrm{LiTiSe}_{2}$ (Figure 4g-4i and Figure S5a, Supporting Information). Notably, the $\mathrm{Li}^{+}$deintercalation ends with the re-formation of $\mathrm{TiSe}_{2}$ phase and no observable unknown phases can be found in Figure 4g-4i, suggesting the excellent reversibility of $\mathrm{Li}^{+}$intercalation, which is similar to the $\mathrm{Li}^{+}$intercalation/deintercalation reaction in $\mathrm{TiS}_{2} \cdot[31,32]$ On the other hand, $\mathrm{TiSe}_{2}$ phase can still be observed after the first $\mathrm{K}^{+}$intercalation reaction, indicating the incomplete potassiation reaction of $\mathrm{TiSe}_{2}$ due to the sluggish reaction kinetics, whereas no $\mathrm{TiSe}_{2}$ phase can be detected for lithium counterpart.

The crystal structure of $\mathrm{TiSe}_{2}$ is illustrated in Figure $4 \mathrm{e}-\mathbf{4 f}$ in order to visually elucidate the structural evolutions. As depicted in Figure 4e-4f, we chose $z$-axis along the $c$-direction to present the $2 \times 2 \times 1$ cell structure of $\mathrm{TiSe}_{2}$ with the octahedral sites $(\mathrm{Oh})$ and the tetrahedral sites (Tr) were schematically labelled. Among the $2 \times 2 \times 1$ cell structure, each Oh site is surrounded by its adjacent four $\mathrm{Tr}$ sites and every single $\mathrm{TiSe}_{2}$ unit has one $\mathrm{Oh}$ site and two $\mathrm{Tr}$ sites. [31, 33-35] Furthermore, the much lower energy barrier of Oh sites $(-0.55 \mathrm{eV})$ compared to $\operatorname{Tr}$ sites $(-0.19 \mathrm{eV})$ was demonstrated favorable towards intercalation of alkali atoms, which was proved by Ramirez et al. through total-energy density functional theory calculations. [35-37] Therefore, the Oh sites at most accommodate one $\mathrm{Li}^{+}$or $\mathrm{K}^{+}$, and thus $\mathrm{TiSe}_{2}$ possesses theoretical capacity of $130.25 \mathrm{~mA} \mathrm{~h} \mathrm{~g}{ }^{-1}$ based on the redox couple of $\mathrm{Ti}^{4+} / \mathrm{Ti}^{3+}$. Here, we re-examine the value of $x$ in $\mathrm{K}_{x} \mathrm{TiSe}_{2}$ after discharging to $1.0 \mathrm{~V}$ from the perspective of capacity. According to the capacity value $\left(136.3 / 92.7 \mathrm{~mA} \mathrm{~h} \mathrm{~g}^{-1}\right.$ at $\left.0.5 \mathrm{C}\right)$ obtained from the discharge/charge curves shown in Figure 2a, the intercalated/deintercalated $\mathrm{K}^{+}$are 
determined to be $\sim 1.05 / 0.71$. And, the specific capacity originated from the GITT profile indicates the intercalated/deintercalated $\mathrm{K}^{+}$is $\sim 1.18 / 0.74$. Considering $\mathrm{TiSe}_{2}$ is not fully involved in the intercalation reaction due to the sluggish reaction kinetics, there is considerable capacity contributed by the electrolyte-involved side reactions. From the above analysis, the number of intercalated $\mathrm{K}^{+}$at the fully discharged state $(1.0 \mathrm{~V})$ should be around 0.7, corresponding to the formation of $\mathrm{K}_{0.7} \mathrm{TiSe}_{2}$. Hence, the phase evolution from $\mathrm{TiSe}_{2}$ to $\mathrm{K}_{x} \mathrm{TiSe}_{2}$ during discharge process can be written as Eq. (3):

$\mathrm{K}+\mathrm{TiSe}_{2} \rightarrow \mathrm{TiSe}_{2}+\mathrm{K}_{0.25} \mathrm{TiSe}_{2} \rightarrow \mathrm{TiSe}_{2}+K_{0.58} \mathrm{TiSe}_{2} \rightarrow \mathrm{TiSe}_{2}+\mathrm{K}_{x} \mathrm{TiSe}$

And the charge process proceeds following Eq. (4):

$K_{x} \mathrm{TiSe}_{2} \rightarrow \mathrm{K}_{0.58} \mathrm{TiSe}_{2} \rightarrow \mathrm{K}_{0.25} \mathrm{TiSe}_{2} \rightarrow \mathrm{K}_{y} \mathrm{TiSe}_{2}+\mathrm{TiSe}_{2}$

With regard to $\mathrm{TiSe}_{2} / \mathrm{Li}$, it is no doubt that $\mathrm{TiSe}_{2}$ experiences a reversible intercalation reaction with one $\mathrm{Li}^{+}$intercalated into $\mathrm{TiSe}_{2}$ host according to the results presented in Figure 4g-4i and Figure S5 (Supporting Information). And the phase evolution during $\mathrm{Li}^{+}$ intercalation reaction can be illustrated by Eq. (5):

$$
\mathrm{Li}+\mathrm{TiSe}_{2} \leftrightarrow \mathrm{Li}_{0.33} \mathrm{TiSe}_{2} \leftrightarrow \mathrm{LiTiSe}_{2}
$$

The chemical compositions of the intermediate phases during $\mathrm{K}^{+} / \mathrm{Li}^{+}$intercalation reaction were determined by ex-situ X-ray photoelectron spectroscopy (XPS), as shown in Figure S11-S12 (Supporting Information). In the discharged state as shown in Figure S11a (Supporting Information), the typical peaks located at $\sim 457$ and $\sim 462.5 \mathrm{eV}$ can be assigned to Ti $2 \mathrm{p}_{3 / 2}$ and Ti $2 \mathrm{p}_{1 / 2}$ electronic configurations, respectively. $[38,39]$ In addition, the $2 \mathrm{p}$ core level peaks of $\mathrm{Ti}$ are broadened into four characteristic peaks, which is a result of the formation of two types of Ti atoms. Among which, the peaks positioned at $\sim 458.5$ and $\sim 464.3$ $\mathrm{eV}$ are characteristic peaks of $\mathrm{Ti}^{4+}$, which can be ascribed to the residual $\mathrm{TiSe}_{2}$. The peaks at $\sim 457.5$ and $\sim 462.5 \mathrm{eV}$ can be attributed to $\mathrm{Ti}^{3+}$ of $\mathrm{K}_{x} \mathrm{TiSe}_{2}$, which are arising from the 
reduction of $\mathrm{Ti}^{4+}$ after $\mathrm{K}^{+}$intercalation. When charged to $3.0 \mathrm{~V}$, the relative intensity of the characteristic peaks of $\mathrm{Ti}^{3+}$ is largely reduced, whereas the intensity of $\mathrm{Ti}^{4+}$ peaks increases significantly, confirming the depotassiation reaction. Besides, characteristic peaks of $\mathrm{K} 2 \mathrm{p}_{3 / 2}$ at $\sim 292.9 \mathrm{eV}$ as well as $\mathrm{K} 2 \mathrm{p}_{1 / 2}$ at $\sim 295.7 \mathrm{eV}$ are observed in the discharged state, indicating the existence of $\mathrm{K}^{+}$in $\mathrm{K}_{x} \mathrm{TiSe}_{2}$.[40] By contrast, in the charged state, the $\mathrm{K} 2 \mathrm{p}_{1 / 2}$ peak at $\sim 295.7 \mathrm{eV}$ totally disappears and the peak intensity of $\mathrm{K} 2 \mathrm{p}_{3 / 2}$ at $\sim 292.9 \mathrm{eV}$ decreases accordingly, revealing the de-composition of $\mathrm{K}_{x} \mathrm{TiSe}_{2}$. With regard to the lithium counterpart, the transformation of $\mathrm{Ti}^{3+}$ and $\mathrm{Ti}^{4+}$ (Figure $\mathrm{S} 12$, Supporting Information) shows similar behaviour during $\mathrm{Li}^{+}$intercalation/deintercalation reaction. The results evidently prove the formation of $\mathrm{LiTiSe}_{2}$ after $\mathrm{Li}^{+}$intercalation as well as the transformation from $\mathrm{LiTiSe}_{2}$ to $\mathrm{TiSe}_{2}$ during $\mathrm{Li}^{+}$deintercalation process.

In order to gain further in-depth understanding of the structural evolutions during $\mathrm{K}^{+} / \mathrm{Li}^{+}$ intercalation/deintercalation processes, ex-situ HRTEM were conducted at the discharged/charged states. Meanwhile, the TEM images at the corresponding states where the HRTEM images were captured are presented in Figure S13 (Supporting Information). Figure 5a displays the HRTEM image at the fully discharged state, and expanded as well as distorted lattice fringes can be observed. The lattice spacing of $0.80 \mathrm{~nm}$, can be assigned to the $(003)$ planes of $\mathrm{K}_{0.58} \mathrm{TiSe}_{2}$ (PDF NO.32-0863), which can be confirmed by the (003) diffraction spots in the corresponding FFT image (Figure 5b). Clearly, the obvious structural distortions caused by intercalation of $\mathrm{K}^{+}$can also be seen in the studies of potassiation of $\mathrm{TiS}_{2}$. $[15,16]$ At the fully charged state, the lattice spacings of 0.29 and $0.31 \mathrm{~nm}$ correspond well with the (002) and (100) facets of $\mathrm{TiSe}_{2}$, respectively (Figure 5a). In the meantime, a set of sharp spots ((002), (100), and (101)) along the zone axis of [1-21] in the FFT (Figure 5d) image further demonstrate the re-formation of $\mathrm{TiSe}_{2}$ after the deintercalation of $\mathrm{K}^{+}$. Figure 5 e shows the HRTEM image of $\mathrm{TiSe}_{2}$ at the fully $\mathrm{Li}^{+}$intercalation stage. In contrast to the $\mathrm{K}^{+}$intercalation depicted in Figure 5a, the expanded lattice spacings of 0.32 and $0.28 \mathrm{~nm}$ can be ascribed to 
the (002) and (011) planes of LiTiSe 2 . Particularly, the FFT image in Figure 5 f clearly reveals the good crystallinity of the generated $\mathrm{LiTiSe}_{2}$ with the diffraction spots of (002), (011), and (012) along the zone axis of [2-1-1]. After fully charged to $3.0 \mathrm{~V}$, the lattice fringe shown in Figure $5 \mathrm{~g}$ can be index to the (002) plane of $\mathrm{TiSe}_{2}$ with a $d$-spacing of $0.29 \mathrm{~nm}$. The (100) and (002) diffraction spots along the zone axis of [-12-1] further confirm the presence of $\mathrm{TiSe}_{2}$. On the basis of the aforementioned analysis, it can be concluded that $\mathrm{TiSe}_{2}$ undergoes a completely reversible $\mathrm{Li}^{+}$intercalation/deintercalation reaction with the reversible formation of $\mathrm{Li}_{0.33} \mathrm{TiSe}_{2}$ and $\mathrm{LiTiSe}_{2}$; whereas the $\mathrm{K}^{+}$intercalation/deintercalation process is partially reversible accompanied with the formation of $\mathrm{K}_{0.25} \mathrm{TiSe}_{2}, \mathrm{~K}_{0.58} \mathrm{TiSe}_{2}$, and $\mathrm{K}_{x} \mathrm{TiSe}_{2}(x \approx 0.7)$.

\section{Conclusion}

In summary, the electrochemical $\mathrm{K}^{+}$and $\mathrm{Li}^{+}$intercalation behaviours in $\mathrm{TiSe}_{2}$ were for the first time reported. The diffusion kinetics of $\mathrm{K}^{+}$and $\mathrm{Li}^{+}$in $\mathrm{TiSe}_{2}$ were systematically studied by means of GITT. The calculated diffusion coefficients of $\mathrm{K}^{+}$are $\sim 1-2$ orders lower than $\mathrm{Li}^{+}$counterpart. On the other hand, the mechanisms for the electrochemical intercalation reactions were also investigated by in-situ XRD, ex-situ XPS, as well as ex-situ TEM. TiSe 2 experiences three phases' stages with partially reversible formation of $\mathrm{K}_{0.25} \mathrm{TiSe}_{2}, \mathrm{~K}_{0.58} \mathrm{TiSe}_{2}$, and $\mathrm{K}_{x} \mathrm{TiSe}_{2} \quad(x \approx 0.7)$ during $\mathrm{K}^{+}$intercalation/deintercalation. Meanwhile, the $\mathrm{Li}^{+}$ intercalation/deintercalation proceeds via completely reversible formation of phases $\mathrm{Li}_{0.33} \mathrm{TiSe}_{2}$ and $\mathrm{LiTiSe}_{2}$. The results would provide new insights into developing intercalation reaction-based electrode materials for rechargeable alkali batteries.

\section{Acknowledgements}

This work is financially supported by Australian Research Council (ARC) through a Linkage Project (LP160100273), a DECRA Grant (DE160100596). This work is also partially supported by AIIM FOR GOLD Grant $(2017,2018)$. The authors acknowledge use of facilities within the UOW electron Microscopy Centre.

\section{Conflict of interest}


The authors declare no competing financial interest.

\section{Reference}

[1] H. Wei, E.F. Rodriguez, A.F. Hollenkamp, A.I. Bhatt, D. Chen, R.A. Caruso, Advanced Functional Materials, 27 (2017).

[2] C. Tang, Y. Liu, C. Xu, J. Zhu, X. Wei, L. Zhou, L. He, W. Yang, L. Mai, Advanced Functional Materials, 28 (2018).

[3] J.C. Pramudita, D. Sehrawat, D. Goonetilleke, N. Sharma, Advanced Energy Materials, (2017).

[4] X. Wu, D.P. Leonard, X. Ji, Chemistry of Materials, 29 (2017) 5031-5042.

[5] Y. Fang, J. Zhang, L. Xiao, X. Ai, Y. Cao, H. Yang, Advanced Science, (2017).

[6] N. Yabuuchi, K. Kubota, M. Dahbi, S. Komaba, Chemical reviews, 114 (2014) 1163611682.

[7] W. Zhang, J. Mao, S. Li, Z. Chen, Z. Guo, Journal of the American Chemical Society, 139 (2017) 3316-3319.

[8] A. Eftekhari, Z. Jian, X. Ji, ACS Applied Materials \& Interfaces, 9 (2017) 4404-4419.

[9] K. Lei, F. Li, C. Mu, J. Wang, Q. Zhao, C. Chen, J. Chen, Energy \& Environmental Science, 10 (2017) 552-557.

[10] I. Sultana, T. Ramireddy, M.M. Rahman, Y. Chen, A.M. Glushenkov, Chemical Communications, 52 (2016) 9279-9282.

[11] Z. Jian, W. Luo, X. Ji, Journal of the American Chemical Society, 137 (2015) 1156611569 .

[12] Z. Jian, Z. Xing, C. Bommier, Z. Li, X. Ji, Advanced Energy Materials, 6 (2016) 1501874.

[13] J. Han, M. Xu, Y. Niu, G.N. Li, M. Wang, Y. Zhang, M. Jia, C.M. Li, Chemical Communications, 52 (2016) 11274-11276.

[14] M. Clites, J.L. Hart, M.L. Taheri, E. Pomerantseva, ACS Energy Letters, 3 (2018) 562567.

[15] B. Tian, W. Tang, K. Leng, Z. Chen, S.J.R. Tan, C. Peng, G.-H. Ning, W. Fu, C. Su, G.W. Zheng, K.P. Loh, ACS Energy Letters, 2 (2017) 1835-1840.

[16] L. Wang, J. Zou, S. Chen, G. Zhou, J. Bai, P. Gao, Y. Wang, X. Yu, J. Li, Y.-S. Hu, H. Li, Energy Storage Materials, 12 (2018) 216-222.

[17] X. Ren, Q. Zhao, W.D. McCulloch, Y. Wu, Nano Research, 10 (2017) 1313-1321.

[18] K. Sato, T. Noji, T. Hatakeda, T. Kawamata, M. Kato, Y. Koike, Journal of the Physical Society of Japan, 86 (2017) 104701.

[19] J. Yang, Y. Zhang, Y. Zhang, J. Shao, H. Geng, Y. Zhang, Y. Zheng, M. Ulaganathan, Z. Dai, B. Li, Y. Zong, X. Dong, Q. Yan, W. Huang, Small, 13 (2017).

[20] Y. Gu, Y. Katsura, T. Yoshino, H. Takagi, K. Taniguchi, Scientific reports, 5 (2015) 12486.

[21] Z. Dan, Z. Guoqiang, L. Peng, Z. Yu, Q. Wenbin, S. Jie, J. Yinzhu, D.S. Xue, S. Wenping, Chemistry - A European Journal, 24 (2018) 1193-1197.

[22] J. Shu, M. Shui, D. Xu, Y. Ren, D. Wang, Q. Wang, R. Ma, W. Zheng, S. Gao, L. Hou, J. Xu, J. Cui, Z. Zhu, M. Li, Journal of Materials Chemistry, 22 (2012) 3035-3043.

[23] D.S. Tchitchekova, A. Ponrouch, R. Verrelli, T. Broux, C. Frontera, A. Sorrentino, F. Bardé, N. Biskup, M.E. Arroyo-de Dompablo, M.R. Palacín, Chemistry of Materials, 30 (2018) 847-856.

[24] S.N. Li, J.B. Liu, B.X. Liu, Journal of Power Sources, 320 (2016) 322-331.

[25] S. Fan, X. Zou, H. Du, L. Gan, C. Xu, W. Lv, Y.-B. He, Q.-H. Yang, F. Kang, J. Li, The Journal of Physical Chemistry C, 121 (2017) 13599-13605. 
[26] H. Wang, Y. Chen, M. Duchamp, Q. Zeng, X. Wang, S.H. Tsang, H. Li, L. Jing, T. Yu, E.H.T. Teo, Z. Liu, Advanced materials, 30 (2018).

[27] W. Weppner, R.A. Huggins, Journal of The Electrochemical Society, 124 (1977) 15691578.

[28] X.H. Rui, N. Yesibolati, S.R. Li, C.C. Yuan, C.H. Chen, Solid State Ionics, 187 (2011) 58-63.

[29] X. Zheng, P. Li, H. Zhu, K. Rui, G. Zhao, J. Shu, X. Xu, W. Sun, S.X. Dou, Energy Storage Materials, 15 (2018) 257-265.

[30] M. Winter, J.O. Besenhard, M.E. Spahr, P. Novák, Advanced materials, 10 (1998) 725763.

[31] M.S. Whittingham, Progress in Solid State Chemistry, 12 (1978) 41-99.

[32] M.S. Whittingham, Science, 192 (1976) 1126-1127.

[33] E.A. Suslov, O.V. Bushkova, E.A. Sherstobitova, O.G. Reznitskikh, A.N. Titov, Ionics, 22 (2015) 503-514.

[34] S.N. Patel, A.A. Balchin, in: Zeitschrift für Kristallographie - Crystalline Materials, 1983, pp. 273-278.

[35] C. Ramírez, R. Adelung, R. Kunz, L. Kipp, W. Schattke, Physical Review B, 71 (2005).

[36] C. Ramirez, W. Schattke, Surface science, 482 (2001) 424-429.

[37] W. Schattke, C. Ramırez, in: Proceedings of NIC Symposium, 2004, pp. 191-200.

[38] P. Li, S. Qian, H. Yu, L. Yan, X. Lin, K. Yang, N. Long, M. Shui, J. Shu, Journal of Power Sources, 330 (2016) 45-54.

[39] H. Li, L. Shen, B. Ding, G. Pang, H. Dou, X. Zhang, Nano Energy, 13 (2015) 18-27.

[40] Y. Dong, Z.-S. Wu, S. Zheng, X. Wang, J. Qin, S. Wang, X. Shi, X. Bao, ACS nano, 11 (2017) 4792-4800. 


\section{Figure Captions}

Figure 1. (a) XRD Rietveld refinement pattern of $\mathrm{TiSe}_{2}$; (b) crystal structure of $\mathrm{TiSe}_{2}$ with octahedral sites (Oh) as well as the adjacent tetrahedral sites (Tr); (c) TEM and (d) HRTEM images of $\mathrm{TiSe}_{2}$; (e) Raman spectra of $\mathrm{TiSe}_{2}$.

Figure 2. (a) The galvanostatic discharge/charge curves of $\mathrm{TiSe}_{2}$ in K-ion battery at $65 \mathrm{~mA} \mathrm{~g}$ ${ }^{1}$ (0.5 C) between 1.0 and $3.0 \mathrm{~V}$; (b) the first three $\mathrm{CV}$ curves of $\mathrm{TiSe}_{2}$ in K-ion battery. (c) The galvanostatic discharge/charge curves of $\mathrm{TiSe}_{2}$ in Li-ion battery at $65 \mathrm{~mA} \mathrm{~g}^{-1}(0.5 \mathrm{C})$ between 1.5 and $3.0 \mathrm{~V}$; (d) the first three $\mathrm{CV}$ curves of $\mathrm{TiSe}_{2}$ in Li-ion battery. Rate capabilities of $\mathrm{TiSe}_{2}$ in (e) K-ion battery and (f) Li-ion battery. (g) Cycling performances of $\mathrm{TiSe}_{2}$ in $\mathrm{K}$-ion and Li-ion batteries at $0.4 \mathrm{~A} \mathrm{~g}^{-1}$.

Figure 3. GITT curves of $\mathrm{TiSe}_{2}$ in K-ion (a) and Li-ion battery (d) as a function of time in the voltage range of 1.0-3.0 $\mathrm{V}$ and 1.5-3.0 V during discharge/charge processes; (b) Scheme for a single step of a GITT experiment for K-ion (b) and Li-ion battery (e) during the first discharge process: $\tau$ (constant current pulse time), $\Delta \mathrm{E} \tau$ (total change of cell voltage during constant current pulse neglecting the IR-drop) and $\Delta$ Es (change of the steady-state voltage). $\mathrm{D}_{\mathrm{K}+}(\mathrm{c})$ and $\mathrm{D}_{\mathrm{Li}+}$ (f) values in the $\mathrm{TiSe}_{2} / \mathrm{K}$ and $\mathrm{TiSe}_{2} / \mathrm{Li}$ cells during the first discharge/charge process.

Figure 4. Structural evolutions of a $\mathrm{TiSe}_{2} / \mathrm{K}$ cell during in-situ XRD discharge/charge processes. The peaks' evolution in the $2 \theta$ rage from 10.0 to $15.0^{\circ}$ (a); from 28.0 to $35.0^{\circ}$ (b); from 38.0 to $43.0^{\circ}$ (c). (d) The corresponding discharge/charge curves of the in-situ $\mathrm{TiSe}_{2} / \mathrm{K}$ cell. (e) Cell structure of $\mathrm{TiSe}_{2}$ along [001] direction before $\mathrm{K}^{+} / \mathrm{Li}^{+}$intercalation process; (f) structure of $\mathrm{TiSe}_{2}$ at the end of intercalation step. Structural evolutions of a $\mathrm{TiSe}_{2} / \mathrm{Li}$ cell during in-situ XRD discharge/charge processes. The peaks' evolution in the $2 \theta$ rage from 11.0 to $16.0^{\circ}(\mathrm{g})$; from 27.0 to $34.0^{\circ}(\mathrm{h})$; from 38.0 to $43.0^{\circ}$ (i). (j) The corresponding discharge/charge curves of the in-situ $\mathrm{TiSe}_{2} / \mathrm{Li}$ cell. 
Figure 5. The ex-situ HRTEM images and corresponding SAED patterns of the $\mathrm{TiSe}_{2} / \mathrm{K}$ cell at a discharged state of (a-b) $1.0 \mathrm{~V}$ and charged state (c-d) of 3.0 V. The ex-situ HRTEM images and corresponding SAED patterns of the $\mathrm{TiSe}_{2} / \mathrm{Li}$ cell at a discharged state of (e-f) 1.5 $\mathrm{V}$ and charged state $(\mathrm{g}-\mathrm{h})$ of $3.0 \mathrm{~V}$. 

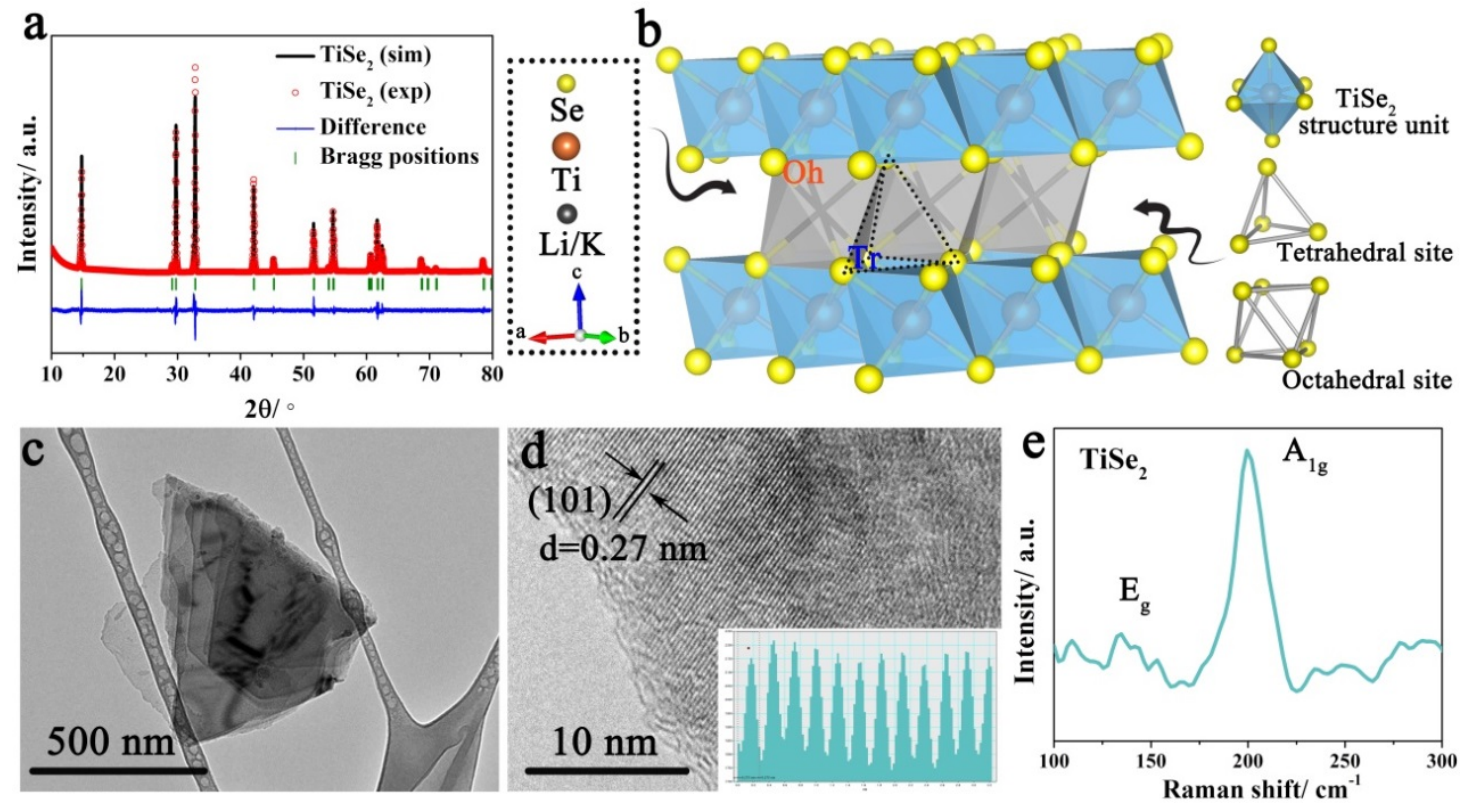

Figure 1. (a) XRD Rietveld refinement pattern of $\mathrm{TiSe}_{2}$; (b) crystal structure of $\mathrm{TiSe}_{2}$ with octahedral sites (Oh) as well as the adjacent tetrahedral sites (Tr); (c) TEM and (d) HRTEM images of $\mathrm{TiSe}_{2}$; (e) Raman spectra of $\mathrm{TiSe}_{2}$. 

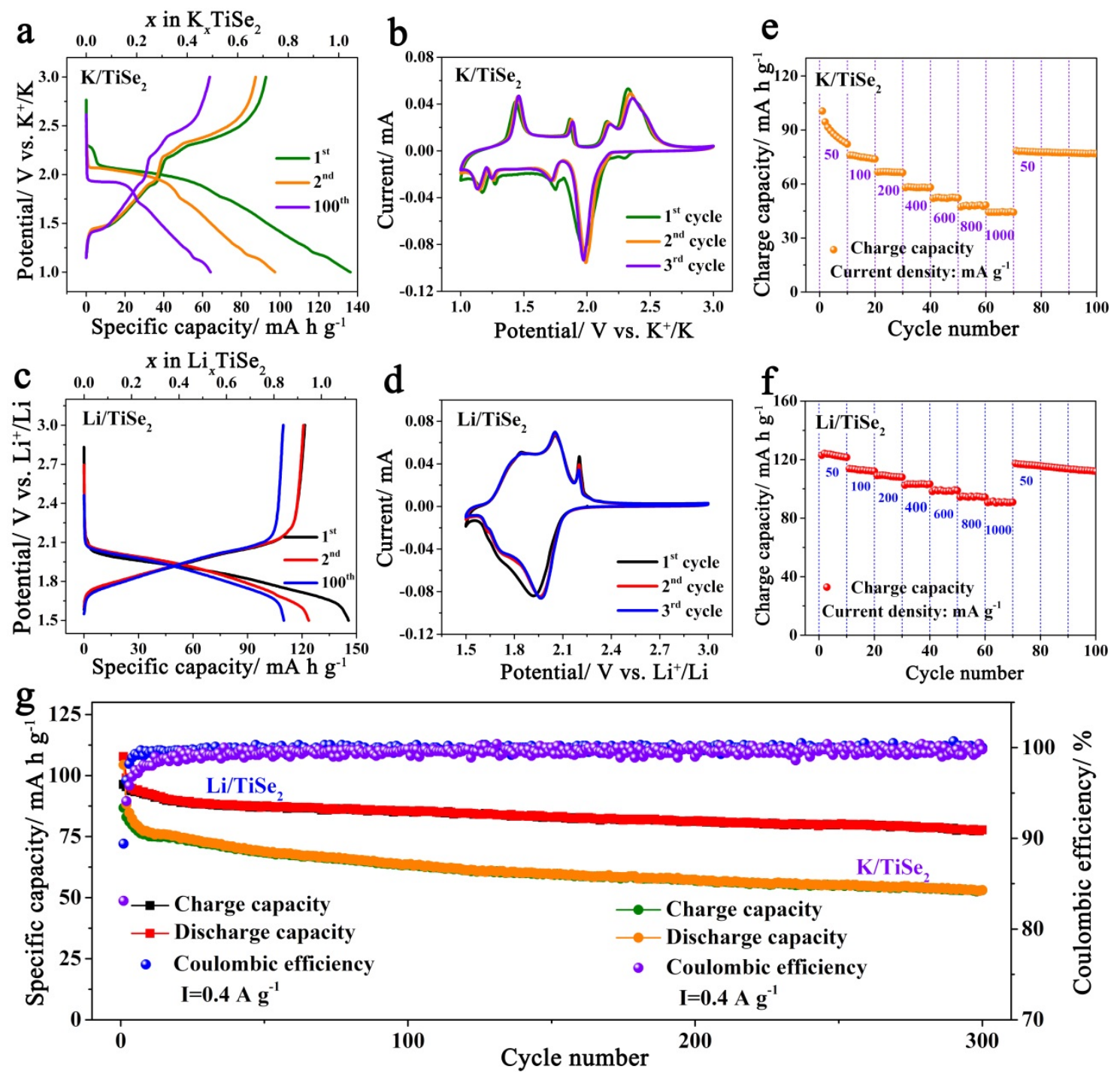

Figure 2. (a) The galvanostatic discharge/charge curves of $\mathrm{TiSe}_{2}$ in K-ion battery at $65 \mathrm{~mA} \mathrm{~g}$ ${ }^{1}(0.5 \mathrm{C})$ between 1.0 and $3.0 \mathrm{~V}$; (b) the first three CV curves of $\mathrm{TiSe}_{2}$ in K-ion battery. (c) The galvanostatic discharge/charge curves of $\mathrm{TiSe}_{2}$ in Li-ion battery at $65 \mathrm{~mA} \mathrm{~g}^{-1}(0.5 \mathrm{C})$ between 1.5 and $3.0 \mathrm{~V}$; (d) the first three $\mathrm{CV}$ curves of $\mathrm{TiSe}_{2}$ in Li-ion battery. Rate capabilities of $\mathrm{TiSe}_{2}$ in (e) K-ion battery and (f) Li-ion battery. (g) Cycling performances of $\mathrm{TiSe}_{2}$ in $\mathrm{K}$-ion and Li-ion batteries at $0.4 \mathrm{~A} \mathrm{~g}^{-1}$. 

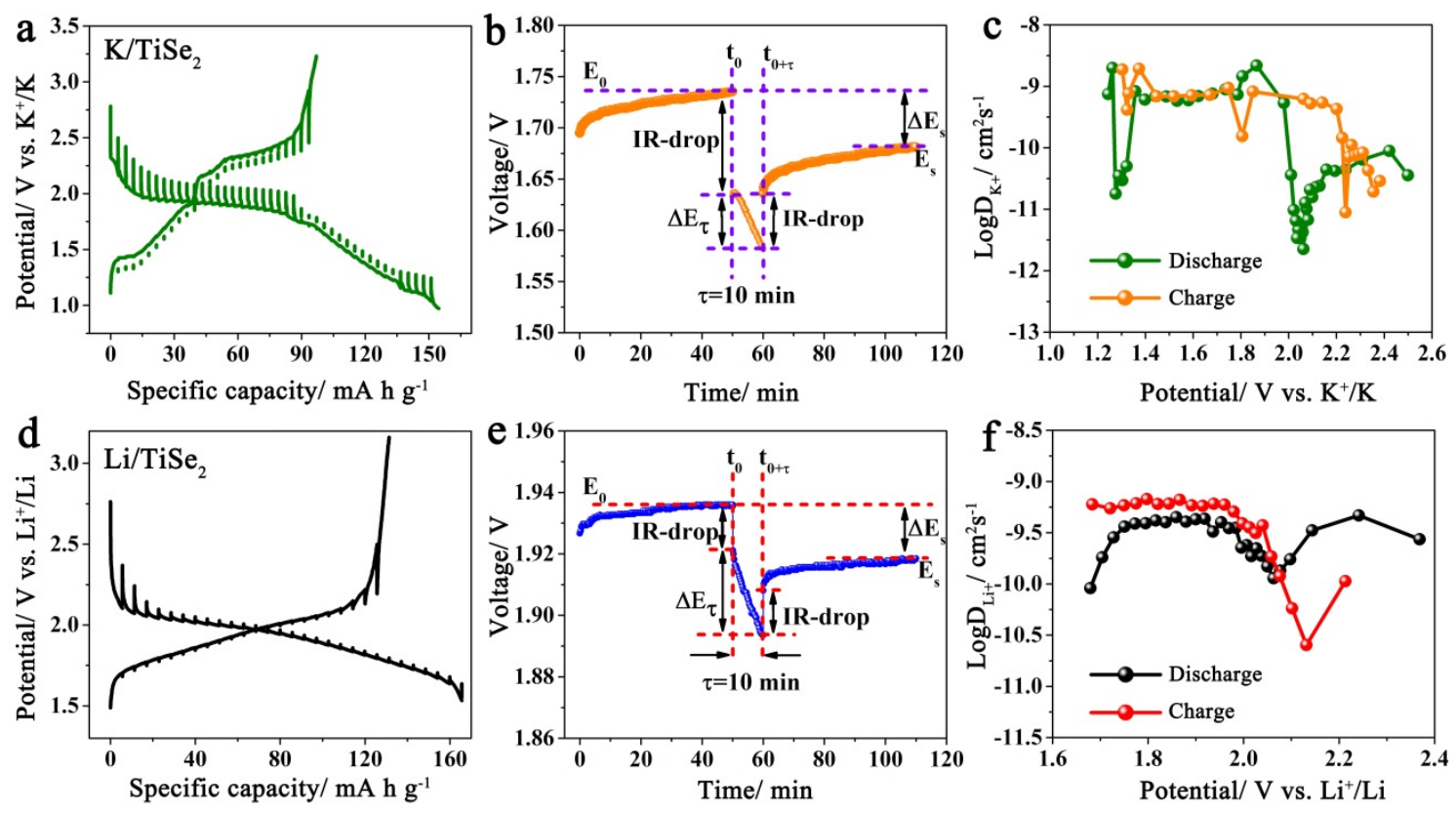

Figure 3. GITT curves of $\mathrm{TiSe}_{2}$ in K-ion (a) and Li-ion battery (d) as a function of time in the voltage range of 1.0-3.0 $\mathrm{V}$ and 1.5-3.0 $\mathrm{V}$ during discharge/charge processes; (b) Scheme for a single step of a GITT experiment for K-ion (b) and Li-ion battery (e) during the first discharge process: $\tau$ (constant current pulse time), $\Delta \mathrm{E} \tau$ (total change of cell voltage during constant current pulse neglecting the IR-drop) and $\Delta$ Es (change of the steady-state voltage). $\mathrm{D}_{\mathrm{K}+}(\mathrm{c})$ and $\mathrm{D}_{\mathrm{Li}}$ (f) values in the $\mathrm{TiSe}_{2} / \mathrm{K}$ and $\mathrm{TiSe}_{2} / \mathrm{Li}$ cells during the first discharge/charge process. 

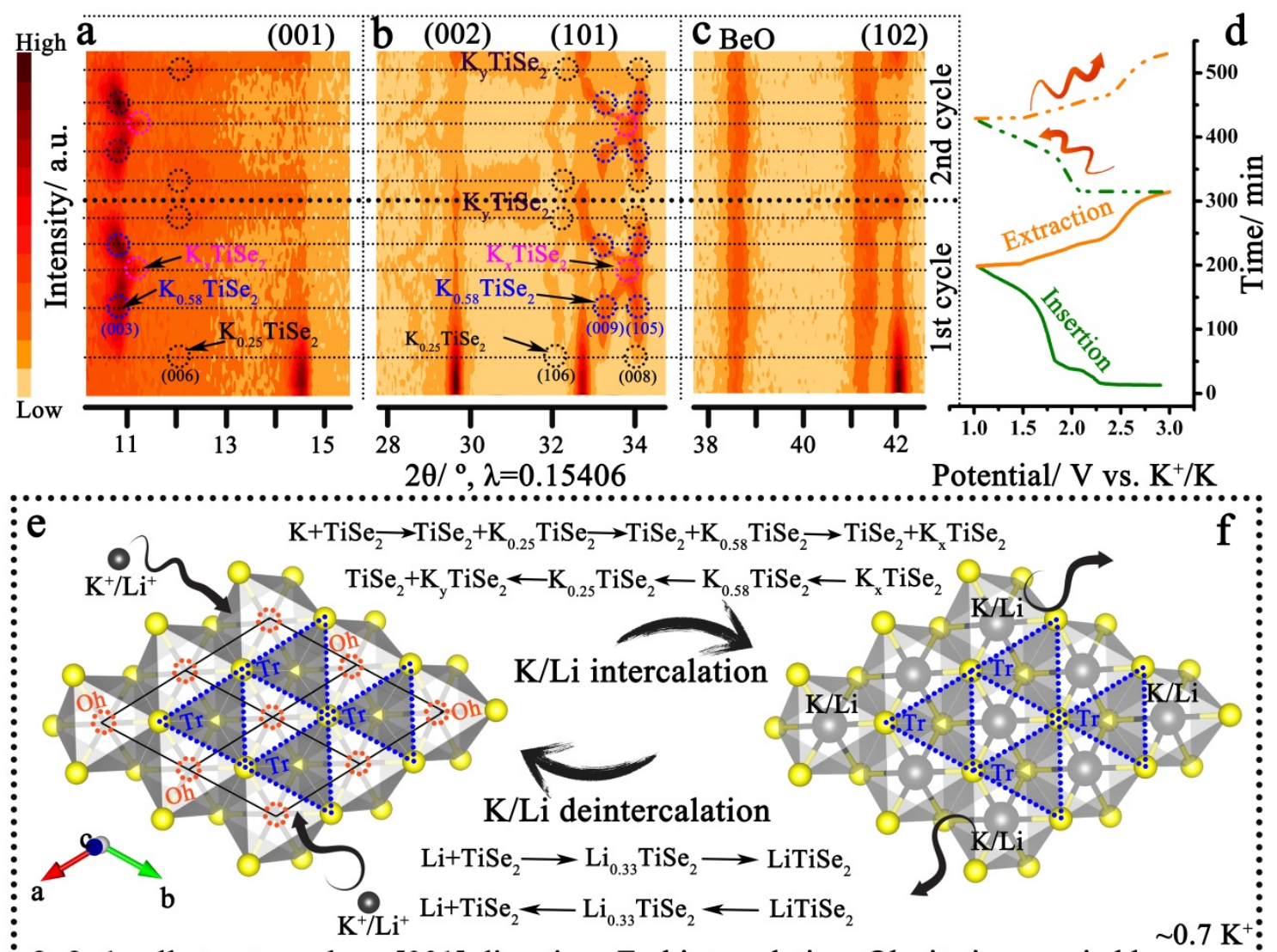

$2 \times 2 \times 1$ cell structure along [001] direction End intercalation: Oh site is occupied by $1 \mathrm{Li}^{+} \vdots$

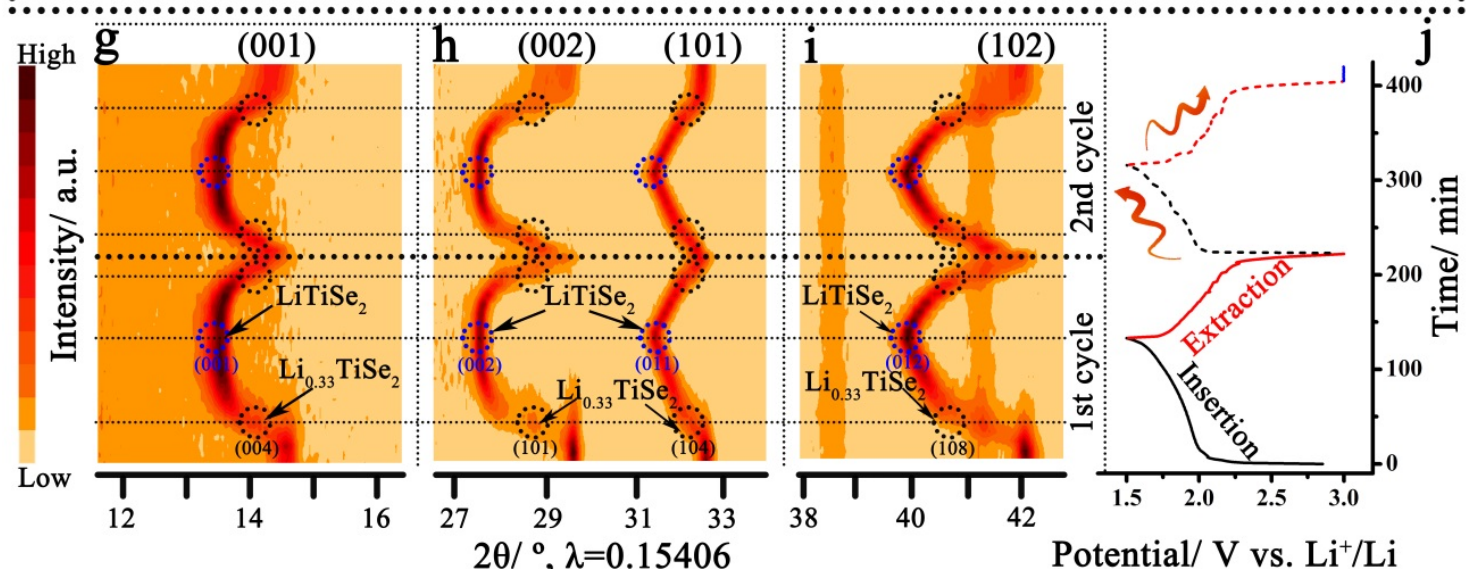

Figure 4. Structural evolutions of a $\mathrm{TiSe}_{2} / \mathrm{K}$ cell during in-situ XRD discharge/charge processes. The peaks' evolution in the $2 \theta$ rage from 10.0 to $15.0^{\circ}$ (a); from 28.0 to $35.0^{\circ}$ (b); from 38.0 to $43.0^{\circ}$ (c). (d) The corresponding discharge/charge curves of the in-situ $\mathrm{TiSe} / \mathrm{K}$ cell. (e) Cell structure of $\mathrm{TiSe}_{2}$ along [001] direction before $\mathrm{K}^{+} / \mathrm{Li}^{+}$intercalation process; (f) structure of $\mathrm{TiSe}_{2}$ at the end of intercalation step. Structural evolutions of a $\mathrm{TiSe}_{2} / \mathrm{Li}$ cell during in-situ XRD discharge/charge processes. The peaks' evolution in the $2 \theta$ rage from 11.0 to $16.0^{\circ}(\mathrm{g})$; from 27.0 to $34.0^{\circ}(\mathrm{h})$; from 38.0 to $43.0^{\circ}$ (i). (j) The corresponding discharge/charge curves of the in-situ $\mathrm{TiSe}_{2} / \mathrm{Li}$ cell. 


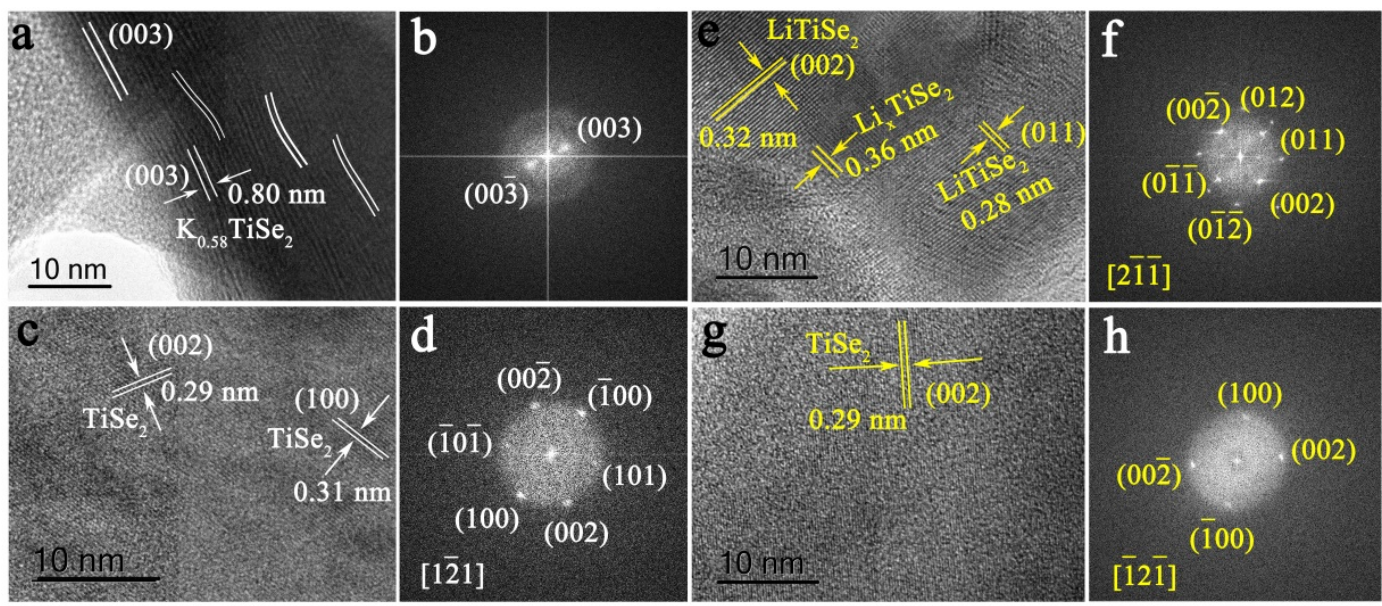

Figure 5. The ex-situ HRTEM images and corresponding SAED patterns of the $\mathrm{TiSe}_{2} / \mathrm{K}$ cell at a discharged state of (a-b) $1.0 \mathrm{~V}$ and charged state (c-d) of $3.0 \mathrm{~V}$. The ex-situ HRTEM images and corresponding SAED patterns of the $\mathrm{TiSe}_{2} / \mathrm{Li}$ cell at a discharged state of (e-f) 1.5 $\mathrm{V}$ and charged state $(\mathrm{g}-\mathrm{h})$ of $3.0 \mathrm{~V}$. 